\title{
Enhanced pressor response to acute Ang II infusion in mice lacking membrane-associated prostaglandin E2 synthase-1
}

\author{
Dong-juan ZHANG ${ }^{1,2}$, Li-hong CHEN ${ }^{1,2}$, Ya-hua ZHANG ${ }^{3}$, Guang-rui YANG ${ }^{1,2}$, Dou DOU ${ }^{1}$, Yuan-sheng GAO ${ }^{1}$, Xiao-yan \\ ZHANG ${ }^{1,2}$, Xiao-mu KONG ${ }^{1,2}$, Pan ZHAO ${ }^{1,2}$, Dan PU ${ }^{1,2}$, Ming-fen WEI ${ }^{1,2}$, Matthew-D BREYER ${ }^{3}$, You-fei GUAN ${ }^{1,2, *}$ \\ ${ }^{1}$ Department of Physiology and Pathophysiology, Peking University Health Science Center, Beijing 100191, China; ${ }^{2}$ Peking University \\ Diabetes Center, Beijing 100191, China; ${ }^{3}$ Division of Nephrology, Vanderbilt University Medical Center, Nashville, TN 37232-2372, \\ USA
}

Aim: To examine the contribution of vascular membrane-associated prostaglandin E2 synthase-1 (mPGES-1) to acute blood pressure homeostasis.

Methods: Angiotensin II (Angll, $75 \mathrm{pmol} \cdot \mathrm{kg}^{-1} \cdot \mathrm{min}^{-1}$ ) was continuously infused via the jugular vein into wild-type and $\mathrm{mPGES}-1^{-/-}$mice for $30 \mathrm{~min}$, and blood pressure was measured by carotid arterial catheterization. RT-PCR and immunohistochemistry were performed to detect the expression and localization of mPGES-1 in the mouse arterial vessels. Mesenteric arteries were dissected from mice of both genotypes to study vessel tension and measure vascular PGE2 levels.

Results: Wild-type and mPGES-1/- mice showed similar blood pressure levels at baseline, and the acute intravenous infusion of Angll caused a greater increase in mean arterial pressure in the mPGES-1 $1^{-1-}$ group, with a similar diuretic and natriuretic response in both groups. mPGES-1 was constitutively expressed in the aortic and mesenteric arteries and vascular smooth muscle cells of wild-type mice. Strong staining was detected in the smooth muscle layer of arterial vessels. Ex vivo treatment of mesenteric arteries with Angll produced more vasodilatory PGE2 in wild-type than in $\mathrm{mPGES}-1^{-/-}$mice. In vitro tension assays further revealed that the mesenteric arteries of $\mathrm{mPGES}-1^{-/-}$mice exhibited a greater vasopressor response to Angll than those arteries of wild-type mice.

Conclusion: Vascular mPGES-1 acts as an important tonic vasodilator, contributing to acute blood pressure regulation.

Keywords: prostaglandin E2; membrane-associated prostaglandin E2 synthase-1; angiotensin II; blood pressure; resistant vessel

Acta Pharmacologica Sinica (2010) 31: 1284-1292; doi: 10.1038/aps.2010.99; published online 27 Sep 2010

\section{Introduction}

Prostanoids are lipid mediators that play important roles in many physiological and pathophysiological processes, including inflammation, renal sodium homeostasis, blood pressure regulation, and tumorigenesis. Prostaglandin E2 (PGE2) is the most common prostanoid produced from three sequential enzymatic reactions. The reactions begin with a release of arachidonic acid from membrane phospholipids by phospholipase A2 (PLA2), followed by the conversion of arachidonic acid to unstable endoperoxide intermediates, PGG2 and PGH2, by cyclooxygenases (COX-1 and -2), and finally the isomerization of PGH2 to PGE2 by terminal PGE2 synthases (PGES).

To date, at least three major forms of PGES have been identi-

\footnotetext{
* To whom correspondence should be addressed.

E-mail youfeiguan@bjmu.edu.cn

Received 2010-04-03 Accepted 2010-06-23
}

fied: membrane-associated PGES (mPGES)-1 and -2 and cytosolic PGES (cPGES). mPGES-1 was the first cloned PGES and is a member of the superfamily of membrane-associated proteins that are involved in eicosanoid and glutathione metabolism ${ }^{[1-3]}$. Similar to COX-2, mPGES-1 is expressed at low levels in most tissues, and its expression can be significantly induced by many proinflammatory factors, cytokines and growth factors, including tumor necrosis factor a and interleukin $1^{[4,5]}$, which suggests that mPGES-1 may be functionally coupled with COX-2 to mediate PGE2 synthesis in response to physiological and pathophysiological stimulation such as acute and chronic inflammatory responses ${ }^{[1,6-9]}$. Coordinate elevation of mPGES-1 and COX-2 expression is present in a number of cancers, including lung, gastric, and colorectal tumors ${ }^{[10,11]}$. Soon after the cloning of mPGES-1, a second putative microsomal PGES (mPGES-2) was identified and characterized ${ }^{[12,13]}$. This enzyme is constitutively expressed in various cell types and tissues and may be functionally linked to both COX-1 and 
$-2^{[14]}$, but its relative contribution to PGE2 generation in vivo remains largely uncharacterized. The third form of PGES (cPGES) was originally isolated from cytoplasmic extracts and is expressed ubiquitously in a constitutive housekeeping manner and functionally coupled with COX-1 to generate physiological PGE2 ${ }^{[15,16]}$.

A large body of evidence demonstrates that PGE2 exerts both vasoconstrictive and vasodilatory actions via its four G-protein coupled receptors: EP1, EP2, EP3, and EP4 $4^{[17,18]}$. However, the net effect of PGE2 appears to be the reduction of blood pressure ${ }^{[19-21]}$. This finding is consistent with clinical observations that nonsteroidal anti-inflammatory drugs (NSAIDs), such as COX inhibitors, can cause hypertension ${ }^{[22-24]}$. Similarly, COX-2 inhibitors increase blood pressure in both animals and patients ${ }^{[25-28]}$, which suggests that COX2-derived prostaglandins are predominantly the vasodilators. Since mPGES-1 is generally believed to be coupled with COX-2 to mediate PGE2 biosynthesis, mPGES-1-derived PGE2 may also exert a vasodepressor effect in vivo. Indeed, recent studies found that deletion of the mPGES-1 gene caused a hypersensitive phenotype in response to chronic salt loading and angiotension II (AngII) infusion, possibly due to impaired renal sodium excretion ${ }^{[29,30]}$. However, studies by two other groups failed to demonstrate the effect of mPGES-1 on blood pressure $^{[31,32]}$. The discrepancies between these studies are currently unknown and may be associated with a difference in feeding protocols and mouse strains used in these studies.

As a major COX product of vascular smooth muscle, PGE2 is critical for the pressor response to AngII in acute AngIIdependent models ${ }^{[17,33]}$. A recent study showed that COX-1derived PGE2 promotes, whereas COX-2-derived PGE2 attenuates, AngII-dependent hypertension ${ }^{[33]}$. In addition, the role of mPGES-1, as a downstream terminal PGE2-synthesizing enzyme that is functionally coupled to COX-2 in regulating blood pressure, has been reported, pointing to a depressor effect of mPGES-1 in blood pressure regulation ${ }^{[30]}$. In the present study, we investigated the role of vascular mPGES-1 in maintaining normal blood pressure. We show that mPGES-1 is expressed in the vascular smooth muscle cells (VSMCs) of arterial vessels, and its deficiency results in reduced PGE2 production and enhanced vasopressor in response to AngII treatment.

\section{Materials and methods}

\section{Materials and animals}

AngII was purchased from Sigma-Aldrich (Saint Louis, Missouri, USA). The RNA isolation reagent RNAtrip was purchased from Applygen (Beijing). RT-PCR involved the GeneAmp PCR system (Applied Biosystems, Foster City, CA) with reagents obtained from Tiangen (Beijing). All reagents used in immunohistochemistry were purchased from Zhongshan Golden Bridge (Beijing), except for rabbit antihuman mPGES-1 antibody (Cayman Chemical, Ann Arbor, MI).

The mPGES-1 ${ }^{-/-}$mice were created as previously des- cribed $^{[34]}$ and were propagated and maintained on a pure C57BL/6 background. Genotypes of mice were routinely determined by PCR analysis with the use of tail genomic DNA. All experiments involved male mice aged 8 to 12 weeks and weighing 20 to $25 \mathrm{~g}$. Mice were housed under specific pathogen-free conditions and had free access to regular chow and water. All procedures were approved by the Institutional Animal Care and Use Committee of Peking University Health Science Center.

\section{Surgical procedures and blood pressure measurements}

Blood pressure was measured by carotid arterial catheterization as previously reported ${ }^{[18]}$. Briefly, after being anesthetized with $80 \mathrm{mg} / \mathrm{kg}$ ketamine (Fort Dodge Laboratories) and 8 $\mathrm{mg} / \mathrm{kg}$ inactin (BYK), mice were placed on a temperaturecontrolled pad set at $37^{\circ} \mathrm{C}$. After tracheostomy, two PE-10 tubes were inserted into the right carotid artery and the jugular vein for blood pressure monitoring and AngII infusion, respectively. Meanwhile, a catheter was inserted into the bladder for urine collection. The catheter in the carotid artery was linked to a Cobe CDX II transducer connected to a pressure analyzer (BPA 400, Micromed) as previously reported $^{[18]}$. The readings of blood pressure at baseline were equilibrated for 30 to 60 min until stable values were obtained. During the procedure, we experienced the death of a few animals, possibly due to severe hypertension induced by AngII infusion.

AngII solution was freshly prepared in normal saline at $1 \times 10^{-6} \mathrm{~mol} / \mathrm{L}$. Mice were continuously infused via the jugular vein with AngII at $75 \mathrm{pmol} \cdot \mathrm{kg}^{-1} \cdot \mathrm{min}^{-1}$ for $30 \mathrm{~min}$. The mean arterial pressure (MAP) was recorded continuously. Urine output and sodium excretion were determined at baseline and after AngII infusion.

\section{RT-PCR analysis}

Total RNA was extracted from thoracic aortas, mesenteric arteries and the kidneys of wild-type and mPGES-1/- mice and reverse transcribed into cDNA. The specific primers for mouse COX-1, COX-2, mPGES-1, and $\beta$-actin are shown in Table 1. The PCR reaction was carried out at $94{ }^{\circ} \mathrm{C}$ for 5 min and then 35 repeats of $94^{\circ} \mathrm{C}, 58{ }^{\circ} \mathrm{C}$, and $72{ }^{\circ} \mathrm{C}$, each for

Table 1. Upstream and downstream oligonucleotide primers used to determine gene expression using RT-PCR.

\begin{tabular}{|c|c|c|c|c|}
\hline Gene & $\begin{array}{l}\text { Forward/ } \\
\text { reverse }\end{array}$ & $\begin{array}{l}\text { Primers sequence } \\
\qquad\left(5^{\prime} \rightarrow 3^{\prime}\right)\end{array}$ & $\begin{array}{l}\text { Product } \\
\text { size (bp) }\end{array}$ & $\begin{array}{l}\text { GenBank } \\
\text { accession }\end{array}$ \\
\hline \multirow[t]{2}{*}{ mPGES-1 } & Forward & CGCGGTGGCTGTCATCA & 205 & NM_022415 \\
\hline & Reverse & AGGGTTGGGTCCCAGGAAT & & \\
\hline \multirow[t]{2}{*}{$\operatorname{cox}-1$} & Forward & GTGGCTATTTCCTGCAGCTC & 209 & NM_008969 \\
\hline & Reverse & CAGTGCCTCAACCCCATAGT & & \\
\hline \multirow[t]{2}{*}{$\operatorname{cox}-2$} & Forward & AGAAGGAAATGGCTGCAGAA & 194 & NM_011198 \\
\hline & Reverse & GCTCGGCTTCCAGTATTGAG & & \\
\hline \multirow[t]{2}{*}{$\beta$-actin } & Forward & AGCCATGTACGTAGCCATCC & 222 & NM_007393 \\
\hline & Reverse & GCTGTGGTGGTGAAGCTGTA & & \\
\hline
\end{tabular}


$30 \mathrm{~s}$, with a final extension at $72{ }^{\circ} \mathrm{C}$ for $7 \mathrm{~min}$. The products underwent electrophoresis in 1.5\% agarose gel in TAE buffer and were visualized after ethidium bromide staining.

\section{Immunohistochemistry}

Immunohistochemistry was performed as previously described ${ }^{[35]}$. Briefly, segments of thoracic aortas, mesenteric arteries and kidneys were isolated from wild-type and mPGES- $1^{-/-}$mice and fixed in $4 \%$ paraformaldehyde overnight at $4{ }^{\circ} \mathrm{C}$. Tissues were dehydrated in an ascending ethanol series, embedded in paraffin and sectioned at $5 \mu \mathrm{m}$. After conventional deparaffinization and hydration, sections were treated with $3 \% \mathrm{H}_{2} \mathrm{O}_{2}$ for 10 min to eliminate endogenous activity of peroxidase and then heated in a microwave oven in $1 \mathrm{mmol} / \mathrm{L}$ EDTA ( $\mathrm{pH}$ 8.0) for antigen retrieval. After being blocked, tissues were incubated with an anti-mPGES-1 antibody $(1: 100)$ overnight at $4{ }^{\circ} \mathrm{C}$. Sections were then washed with PBS and incubated in a horseradish peroxidase-conjugated goat anti-rabbit IgG for $1 \mathrm{~h}$ at room temperature. Positive staining was revealed by use of diaminobenzidine (DAB, horseradish peroxidase substrate) staining.

\section{Cell culture}

Mouse VSMCs were prepared from the thoracic aortas of 1-month-old male C57BL/6 mice, as previously described ${ }^{[36]}$ with modification. Briefly, after removal of the connective tissue and blood, mouse aortas were incubated in an enzyme solution containing $1 \mathrm{mg} / \mathrm{mL}$ collagenase I (Sigma) for about $7 \mathrm{~h}$ in $95 \%$ air $/ 5 \% \mathrm{CO} 2$ at $37^{\circ} \mathrm{C}$. Then, the aorta was triturated using a fire-polished Pasteur pipette to obtain a cell suspension, and the cells were cultured in DMEM containing $10 \% \mathrm{FBS}, 100 \mathrm{U} / \mathrm{mL}$ penicillin, and $100 \mathrm{mg} / \mathrm{mL}$ streptomycin. All experiments were performed on cells at passages 4 to 6 .

\section{Vessel tension study}

Mesenteric arteries were dissected from male wild-type and $\mathrm{mPGES}-\mathrm{-}^{-/-}$mice and cut into 5 -mm long rings in icecold modified Krebs-Ringer bicarbonate buffer $(\mathrm{NaCl}, 118.3$ $\mathrm{mmol} / \mathrm{L} ; \mathrm{KCl}, 4.7 \mathrm{mmol} / \mathrm{L} ; \mathrm{CaCl}_{2}, 2.5 \mathrm{mmol} / \mathrm{L} ; \mathrm{MgSO}_{4}, 1.2$ $\mathrm{mmol} / \mathrm{L} ; \mathrm{KH}_{2} \mathrm{PO}_{4}, 1.2 \mathrm{mmol} / \mathrm{L} ; \mathrm{NaHCO}_{3}, 25.0 \mathrm{mmol} / \mathrm{L}$; glucose, $11.1 \mathrm{mmol} / \mathrm{L}$ ). The arterial rings were suspended in organ chambers filled with $15 \mathrm{~mL}$ of the modified KrebsRinger bicarbonate solution maintained at $37.0 \pm 0.5^{\circ} \mathrm{C}$ and aerated with $95 \% \mathrm{O}_{2}-5 \% \mathrm{CO}_{2}$ (pH 7.4). Two stirrups passing through the lumen suspended each ring. One stirrup was anchored to the bottom of the organ chamber; the other was connected to a strain gauge. The isometric force was measured with use of a ML785 PowerLab/8sp recording and Analysis System (AD Instruments, Castle Hill, Australia) ${ }^{[37]}$.

At the beginning of the experiment, each vessel ring was stretched to its optimal resting tension by step-wise stretching until the active contraction of the vessel ring in response to 100 $\mathrm{mmol} / \mathrm{L} \mathrm{KCl}$ reached a plateau. The optimal resting tension of mesenteric arteries was $\sim 0.6 \mathrm{~g}$. After the vessels were brought to their optimal resting tension, the system was allowed to equilibrate for $1 \mathrm{~h}$. Then, a dose-response curve to AngII and other vasoactive agents applied to the vessels was constructed in a cumulative fashion.

\section{Enzyme immunoassay}

The mesenteric arteries were dissected from each mouse, cleaned of adhering perivascular tissue, washed three times in PBS, placed in culture flasks at $37^{\circ} \mathrm{C}$ in a humidified atmosphere of $95 \%$ air- $5 \% \mathrm{CO}_{2}$ and cultured in DMEM containing $20 \% \mathrm{FBS}$, streptomycin $(100 \mathrm{mg} / \mathrm{mL})$, and penicillin $(100$ units $/ \mathrm{mL}$ ). After $2 \mathrm{~h}$ of culture, $10^{-6} \mathrm{~mol} / \mathrm{L}$ AngII was added for $30 \mathrm{~s}$, and the supernatant was collected to measure secreted PGE2 by use of a PGE2 enzyme immunoassay (EIA) kit (Cayman Chemical, Ann Arbor, MI) following the manufacturer's instructions.

To analyze tissue levels of PGE2, mesenteric arteries were homogenized in a specific buffer $(0.1 \mathrm{~mol} / \mathrm{L}$ phosphate, $\mathrm{pH} 7.4$, containing $1 \mathrm{mmol} / \mathrm{L}$ EDTA and $10 \mu \mathrm{mol} / \mathrm{L}$ indomethacin), and PGE2 was measured as mentioned above.

\section{Statistical analysis}

Prism GraphPad 4.0 software was used for statistical analysis. The results are expressed as means \pm SEM. In all experiments, data were evaluated by 2-tailed Student's $t$ test and 2-way ANOVA, when appropriate. A $P<0.05$ was considered statistically significant.

\section{Results}

Role of mPGES-1 in the pressor response to acute Angll infusion Since mPGES-1 $1^{-/-}$mice were created with partial deletion of the second exon ${ }^{[34]}$, a truncated $115 \mathrm{bp}$ RT-PCR product was amplified in mPGES-1 gene-deficient mice (Figure 1A). As expected, no full-length mPGES-1 protein (16 kDa) was detected in kidneys of mPGES-1 ${ }^{-/-}$mice as assessed by Western blot (Figure 1A). To examine whether mPGES-1 disruption affects the vascular response to vasoactive substances, the acute pressor response to AngII infusion $\left(75 \mathrm{pmol} \cdot \mathrm{kg}^{-}\right.$ $\left.{ }^{1} \cdot \mathrm{min}^{-1}\right)$ was determined using an indwelling carotid catheter in anesthetized male mice. Baseline blood pressure between mPGES- $1^{-/-}$and wild-type mice did not differ (MAP, 96.3 \pm 2.8 $\mathrm{mmHg}$ os $92.2 \pm 1.9 \mathrm{mmHg}$, respectively) under the anesthetized condition (Figure 1B). However, MAP was significantly higher in mPGES-1 ${ }^{-/-}$than in wild-type mice after AngII infusion (peak MAP 134.5 \pm 4.3 vs $119.3 \pm 3.9 \mathrm{mmHg}$; $P<0.05$; Figure 1B). Over the 30-min AngII infusion, MAP was approximately $18 \mathrm{mmHg}$ higher, on average, in PPGES- $^{-1 /}$ mice than in $\mathrm{mPGES}-1^{+/+}$mice; this increase in the hypertensive response to AngII was sustained for the duration of the infusion (Figure 1B). To examine whether mPGES-1 disruption affects vascular response to other vasoconstrictors, the acute pressor response to phenylephrine (56 $\mathrm{\mu g} / \mathrm{kg}$, bolus injection) ${ }^{[38]}$ was determined. As shown in Figure 1C, phenylephrine administration resulted in a marked increase in blood pressure in both genotypes. However, there was no statistical difference between wild type and $\mathrm{mPGES}-1^{-/-}$mice, suggesting that the difference in vascular response to AngII infusion between wild-type and 
A
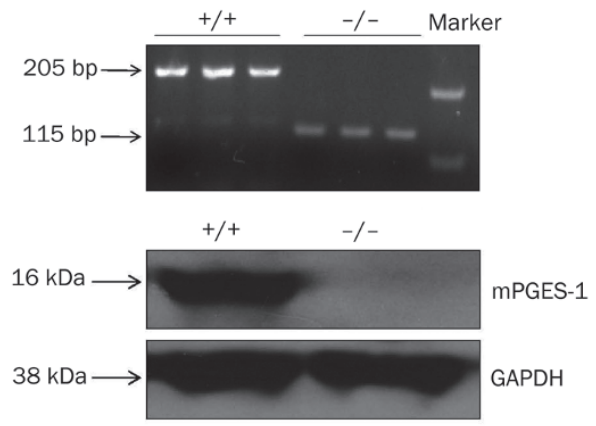

B
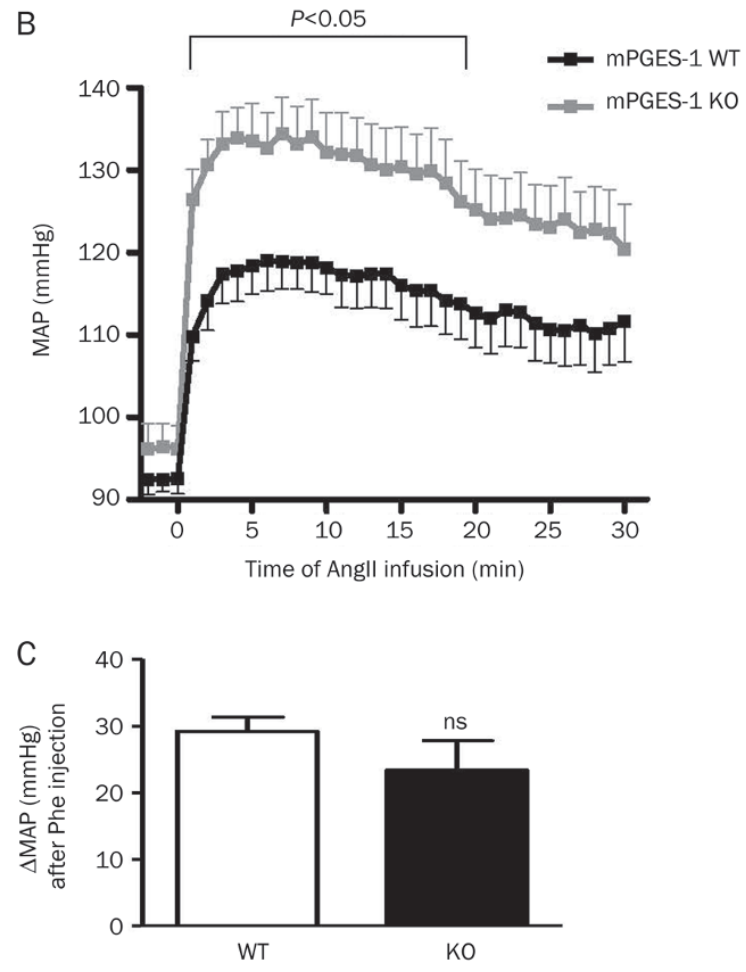

Figure 1. Acute Angll infusion resulted in a more prominent elevation of mean arterial pressure (MAP) in $\mathrm{mPGES}-1^{-1-}$ mice than in wild type mice. (A) RT-PCR (upper panel) and immunoblot (lower panel) analysis demonstrating disruption of mPGES-1 mRNA and protein. Upper panel: RT-PCR assay of total RNA from kidneys of wild-type (WT) and mPGES-1 $1^{-/-}$ (KO) mice. Primers were chosen to amplify the cDNA sequence coding the second exon. PCR with this set of primers yielded a 205-bp PCR product in wild-type mice and a 115-bp product in $\mathrm{mPGES}-1^{-/-}$mice due to a deletion in the second exon; Lower panel: Western blot showing that the full-length (16 kDa) mPGES-1 protein was present in wild-type but not in mPGES-1 deficient kidneys, (B) Effect of acute Angll $\left(75 \mathrm{pmol} \cdot \mathrm{kg}^{-1} \cdot \mathrm{min}^{-1}\right)$ infusion on MAP in mPGES-1 ${ }^{-/-}(K O ; n=12)$ and wild type (WT; $\left.n=11\right)$ mice. Data are means \pm SEM. $P<0.05$. (C) Effect of acute phenylephrine (56 $\mu \mathrm{g} / \mathrm{kg})$ injection on MAP in mPGES-1 ${ }^{-/-}(\mathrm{KO} ; n=3)$ and wild type (WT; $\left.n=3\right)$ mice. Net changes in blood pressure are shown. Data are means $\pm S E M$; ns, no statistical difference.

mPGES- $1^{-/-}$mice is not due to a generalized change in vascular responsiveness but instead to targeting mPGES-1-derived PGE2 production.
Diuretic and natriuretic responses to acute Angll infusion in mPGES-1 ${ }^{-/-}$and wild-type mice

Emerging evidence suggests that PGE2 contributes to blood pressure control via the modulation of both renal function and vascular tone ${ }^{[39]}$. To determine the renal contribution to altered pressor response to acute infusion of AngII, we compared the water and sodium excretion of $\mathrm{mPGES}-1^{-/-}$and wild-type mice. Urine was collected from mice before and after AngII infusion. Urine output and sodium excretion were similar between mPGES-1/- and wild-type mice at baseline (Figures 2A \& 2B). After a 30-min AngII infusion, urine volume and sodium excretion were significantly increased in both groups. However, the extent of the increase in water and sodium excretion did not differ between mPGES-1 ${ }^{-/-}$and wildtype mice (Figures $2 \mathrm{~A} \& 2 \mathrm{~B}$ ).
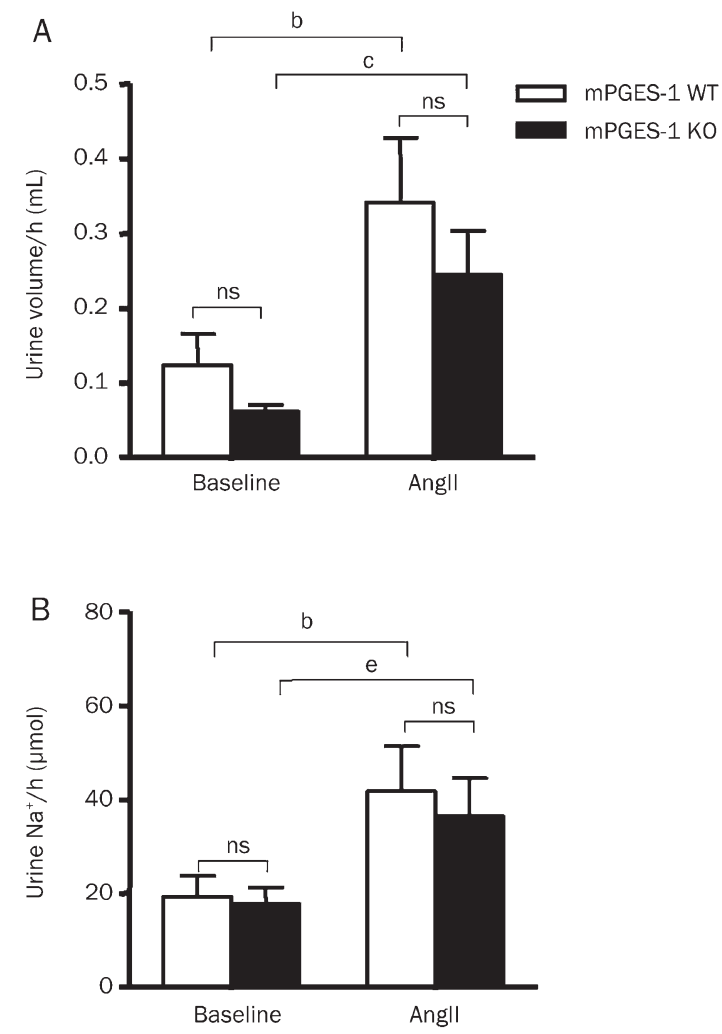

Figure 2. Similar diuretic and natriuretic effect of Angll infusion in mPGES-1 $1^{-/-}$and wild-type mice. (A) Urine volume was similarly increased in both $\mathrm{mPGES}-1^{-/-}(\mathrm{KO}, n=12)$ and wild-type $(\mathrm{WT}, n=11)$ mice infused with Angll $\left(75 \mathrm{pmol}^{\mathrm{kg}} \mathrm{kg}^{-1} \cdot \mathrm{min}^{-1}\right)$ for $30 \mathrm{~min} .{ }^{\mathrm{b}} \mathrm{P}<0.05$ vs WT baseline; ${ }^{\mathrm{C}} P<0.01$ vs KO baseline; ns, no statistical difference. (B) Urine sodium excretion was increased in both $\mathrm{mPGES}-1^{-/-}$and wild-type mice infused with Angll. ${ }^{\mathrm{b}} P<0.05$ vs WT baseline; ${ }^{\mathrm{e}} P<0.05$ vs KO baseline; ns, no statistical difference.

\section{Vascular expression of MPGES-1}

RT-PCR analysis revealed that mPGES-1 was constitutively expressed in various vessels, including the thoracic aorta and mesenteric artery (Figure 3A). As expected, COX-2 and COX-1 


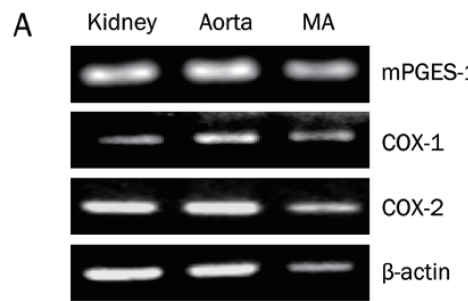

C Cultured mouse vSMCs

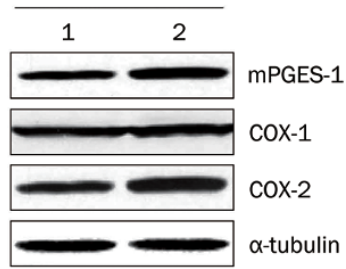

B

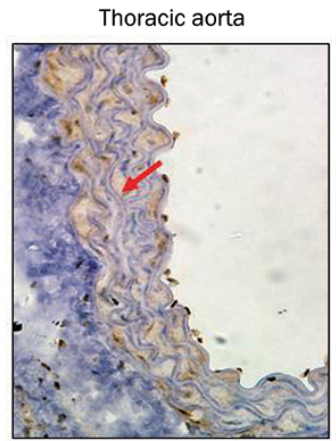

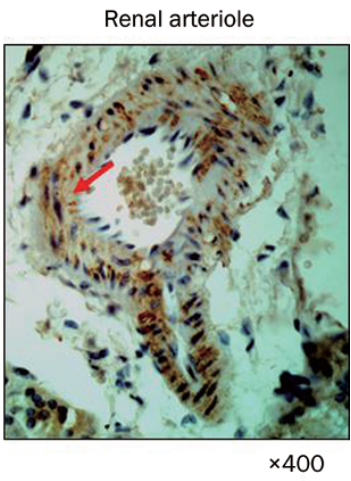

Figure 3. Vascular expression of mPGES-1 and other PGE2 synthases. (A) RT-PCR assay showing mPGES-1, COX-1 and COX-2 mRNA expression in mouse kidneys, thoracic aortas, and mesenteric arteries (MA). Tissue pooled from 3 mouse aortas or 6 mesenteric arterial preparations were collected, and total RNA was extracted and analyzed as described in Materials and Methods. RNA loading control was assessed by simultaneous amplification of B-actin; (B) Immunostaining showing localization of mPGES-1 protein in thoracic aorta, mesenteric arteries, and renal arteriole. Positive staining (brown color, arrows) was visible in the vascular smooth muscle cells of all arterial sections. Magnification: $\times 400$; (C) Immunoblot analysis showing constitutive expression of mPGES-1, COX-1 and COX-2 in cultured vascular smooth muscle cells. Tubulin was used as a loading control. Samples \#1 and \#2 represent two preparations of VSMCs.

were also present in these vessels. Immunohistochemical analysis further revealed mPGES-1 immunoreactivity in multiple vascular beds, including the renal arteriole, aorta and mesenteric artery (Figure 3B). Vascular mPGES-1 was mainly localized in the smooth muscle layer, a result further supported by constitutive protein expression of mPGES-1 in cultured mouse VSMCs, as assessed by Western blot (Figure $3 C)$.

\section{Mesenteric arterial tension study}

Having confirmed that the mesenteric artery, a systemic resistance vessel, expresses mPGES-1 (Figure 3), thus supporting a model in which mPGES-1-derived PGE2 directly exerts its systemic depressor activity on arterial resistance vessels, we next examined the vasopressor effect of AngII on isolated mesenteric arteries from mPGES-1/- and wild-type mice. AngII induced an obvious contraction of the mesenteric arteries isolated from both mPGES-1 ${ }^{-/-}$and wild-type mice. The maximal contraction was obtained at $10^{-7.5} \mathrm{~mol} / \mathrm{L}$ (Figure 4A). However, the contraction was more robust in arteries from mPGES- $1^{-/-}$than in those from wild-type mice. At the concentration of $10^{-7.5} \mathrm{~mol} / \mathrm{L}$, AngII induced a $12 \%$ increase in tension in arteries from mPGES-1 ${ }^{-/-}$mice compared to a $4 \%$ increase in tension in those from wild-type mice $(P<0.05)$. A stronger contraction in response to AngII at $10^{-7} \mathrm{~mol} / \mathrm{L}$ was also found in arteries from mPGES-1 $1^{-/-}$than in arteries from wild-type mice (Figure $4 \mathrm{~A}$ ). To determine whether this difference is a result of a generalized defect in vascular responsiveness in mPGES-1/- $1^{-1}$ mice, we examined the vascular response to phe- nylephrine. As shown in Figure 4B, phenylephrine treatment resulted in a dose-dependent vasoconstriction in both mPGES$1^{-/-}$and wild-type mice. However, there was no statistic difference between the two genotypes, supporting our conclusion that the exaggerated vasopressor effect of AngII in mPGES$1^{-/-}$mice is a result of mPGES- 1 dysfunction rather than a generalized change in vascular responsiveness. Furthermore, the response of mesenteric arteries to $100 \mathrm{mmol} / \mathrm{L} \mathrm{KCl}$ was similar in both genotypes (Figure 4C).

\section{Role of $\mathrm{mPGES}-1$ in vascular PGE2 production}

To examine the role of mPGES-1 in vascular PGE2 production, PGE2 levels were measured in freshly isolated mesenteric arteries. As shown in Figure 5A, the basal levels of vascular PGE2 were significantly lower in mesenteric arteries isolated from mPGES-1 ${ }^{-/-}$mice than in those from wild-type mice $(P<0.05)$. Furthermore, mesenteric arteries from mPGES-1 $1^{-/-}$ mice produced much less PGE2 than the vessels from wildtype mice $(P<0.01)$. Treating vessels with AngII caused a $40 \%$ increase in PGE2 secretion into the supernatant of cultured wild-type arteries, with no significant increase in mPGES- $^{-1 /-}$ mesenteric arteries (Figure 5B), which suggests that mPGES-1 is essential for vascular PGE2 release.

\section{Discussion}

The present study demonstrates that vascular mPGES-1derived PGE2 is involved in acute blood pressure regulation and that inhibition of mPGES-1 activity may diminish the buffering effect of PGE2 on AngII-dependent hypertension. 

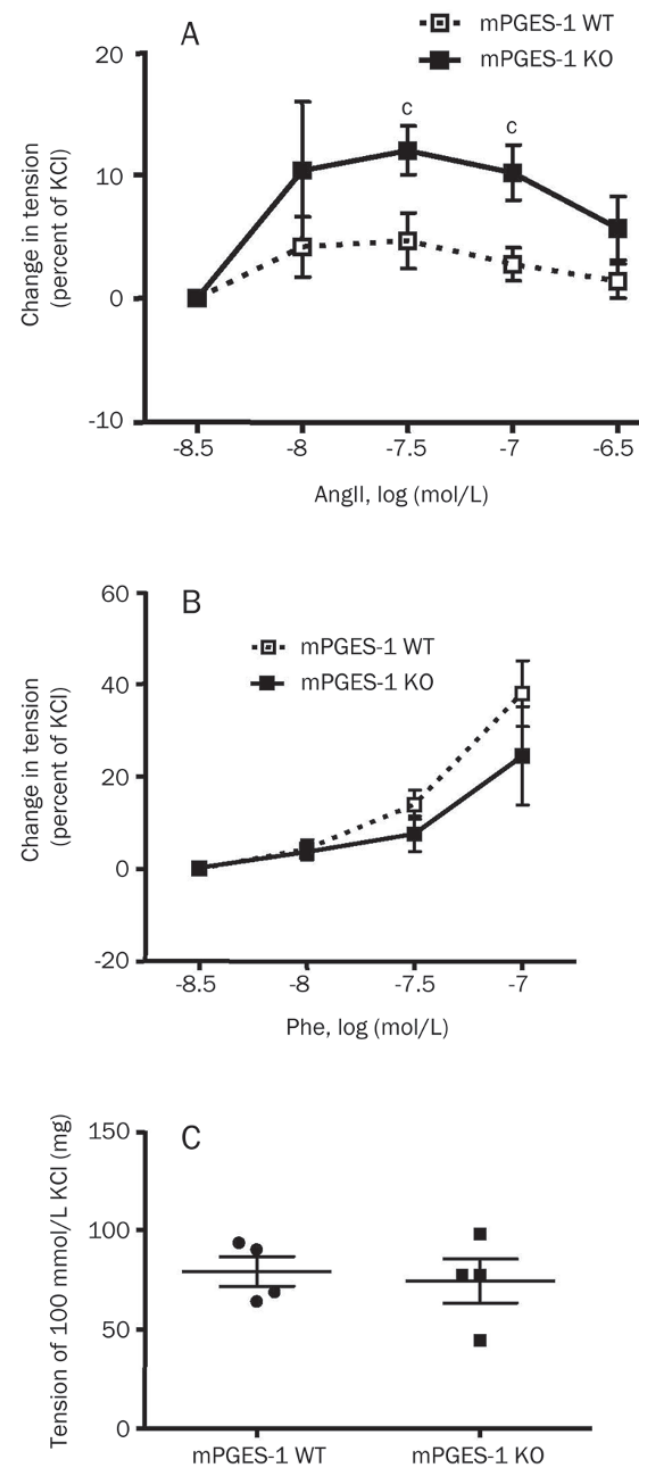

Figure 4. Exaggerated vasoconstriction in response to Angll in mesenteric arteries isolated from $\mathrm{mPGES}-1^{-/-}$mice. Mesenteric arteriolar rings were isolated from $\mathrm{mPGES}-1^{-/-}(\mathrm{KO})$ and wild-type (WT) mice. After obtaining a stable tension in $100 \mathrm{mmol} / \mathrm{L}$ of $\mathrm{KCl}$, different doses of Angll or phenylephrine were added. The change in arterial tension was measured and expressed as the percentage increase over the levels at 100 $\mathrm{mmol} / \mathrm{L}$ of $\mathrm{KCl}$. (A) Angll caused vessel constriction in arteries from both mPGES-1 $1^{-/-}$and wild-type mice, but the increase was greater in arteries from $\mathrm{mPGES}-1^{-/-}$mice than from wild-type mice. Data are means \pm SEM. $n=4$ for each group. ${ }^{c} P<0.01$ vs wild-type. (B) Phenylephrine treatment resulted in a dose-dependent vasoconstriction in both $\mathrm{mPGES}-1^{-1-}$ and wild-type mice. However, there was no statistic difference between two genotypes. $n=4$ for each group. (C) The maximal change in tension of arteries treated with $100 \mathrm{mmol} / \mathrm{L} \mathrm{KCl}$ was similar in both genotypes.

This conclusion is supported by the findings that genetic disruption of mPGES-1 in mice following $30 \mathrm{~min}$ of AngII infusion was associated with a sustained increase in blood pressure without changes in urine output and sodium excretion. A role for mPGES-1 in blood pressure regulation
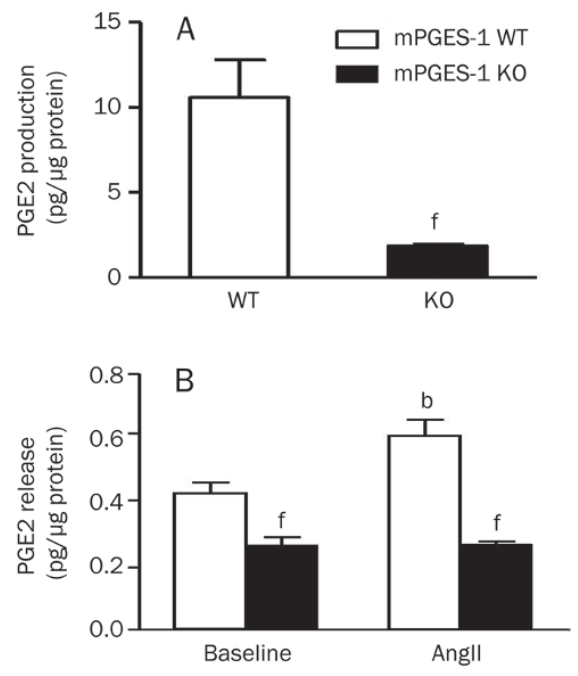

Figure 5. Basal production and Angll-induced PGE2 release in mesenteric arteries from wild-type and mPGES-1 ${ }^{-/-}$mice. (A) PGE2 levels in mesenteric arteries isolated from wild-type and $\mathrm{mPGES}-1^{-/-}$mice were determined by enzyme immunoassay. $n=3$ for each group. ${ }^{c} P<0.01$ vs arteries from wild-type mice. (B) PGE2 release into the supernatant from cultured mesenteric arteries of wild-type (WT) and mPGES-1 $1^{-/-}(\mathrm{KO})$ mice. Mesenteric arteries were isolated from $\mathrm{mPGES}-1^{-/-}$and wild-type mice and cultured in the presence or absence of Angll $\left(10^{-6} \mathrm{~mol} / \mathrm{L}\right)$ for $30 \mathrm{~s}$. The amount of PGE2 secretion in the supernatant was determined. Data are expressed as means \pm SEM. $n=8$ for each group. ${ }^{\mathrm{b}} P<0.05$ vs baseline level; ${ }^{f} P<0.01$ vs wild type.

is further supported by the results that AngII treatment led to much greater vasoconstriction in isolated mesenteric arteries of mPGES-1 $1^{-/-}$than in arteries from wild-type mice. Our results add to previous studies, which have shown that endogenous COX products contribute to the vasoconstrictor activity of AngII ${ }^{[17,33]}$ and are consistent with the prior finding that the effects of prostaglandin synthase inhibition by NSAIDs increases blood pressure ${ }^{[22,23]}$.

Accumulating evidence supports an important role for vasodilator prostanoids in preventing hypertension in humans ${ }^{[17,40]}$. Controlling blood pressure in patients with essential hypertension is particularly dependent on endogenous vasodilator prostaglandins. In mice with targeted disruption of the AngII receptor, increased synthesis of dilator prostaglandins, including PGE2, helps maintain blood pressure homeostasis, and hypertension develops with NSAID treatment $t^{[41]}$. To date, multiple mechanisms have been proposed to mediate the effects of PGE2 on blood pressure, including inhibition of sympathetic nervous activity, decreasing renin release, increasing urine sodium excretion and directly acting on blood vessels ${ }^{[18,42,43]}$. Although mPGES-1, as an inducible terminal PGES, acts in concert with both COX-1 and COX-2 to generate PGE2 ${ }^{[10,44,45]}$, the coupling of mPGES-1 with COX-2 in PGE2 synthesis may play an important role in hypertension because both enzymes are expressed at low levels in vascular beds ${ }^{[46-48]}$ but are significantly induced by AngII ${ }^{[29,49-51]}$. The role for mPGES- 1 in hypertension has been 
an interest of many groups $[29,31,32,39,52]$. Using another line of mPGES-1 ${ }^{-/-}$mice generated independently by Trebino et al $l^{[7]}$, Jia et al found that more severe hypertension developed in mice deficient in mPGES-1 after a 7-day high-salt diet plus salt drink $^{[29,30]}$. This exaggerated hypertensive response may be due in part to the inability of the kidneys of mPGES-1 $1^{-/-}$mice to sufficiently excrete the sodium load. However, whether mPGES-1 is essential for high salt-induced hypertension is a matter of debate because of inconsistent findings ${ }^{[31,32]}$. Therefore, whether vascular mPGES-1 is involved in blood pressure regulation and contributes to salt-sensitive hypertension remains unclear ${ }^{[39]}$.

In the present study, we demonstrated that mPGES-1, along with COX-1 and COX-2, was expressed in many vascular beds, including elastic (thoracic aorta) and resistant (mesenteric artery) vessels. Vascular expression of mPGES-1 was mainly localized in the smooth muscle layers of the vessels, which was further supported by a constitutive expression of mPGES-1 in cultured VSMCs. Ablation of the mPGES-1 gene significantly reduced basal PGE2 production in mesenteric arteries. These findings are in agreement with a previous report $^{[53]}$, which suggests that mPGES-1 is the main PGES isoform responsible for PGE2 biosynthesis in human VSMCs. Co-expression of mPGES-1 with either COX-1 or COX-2 further suggests that mPGES-1 may be functionally coupled with both COX isoforms to mediate PGE2 biosynthesis in vascular beds under physiological conditions.

PGE2 plays an important role in regulating vascular tone and blood pressure. It exerts either vasodilatory or vasoconstrictive action depending on the activation of its four EP receptors $^{[54]}$. Induction of hypertension following NSAID and COX-2 inhibitor treatment indicates that the net effect of endogenous PGE2 is vasodilation ${ }^{[23,40]}$. In support, the present studies provide further evidence that endogenous PGE2 acts as a vasodepressor since acute infusion of AngII resulted in a marked and sustained elevation of blood pressure in mPGES$1^{-/-}$mice compared with wild-type mice. In our present study, we speculated that the effect of renal mPGES-1 may not be apparent during the short term AngII infusion since there was no significant difference in urine output and sodium excretion between wild-type and mPGES-1 ${ }^{-/-}$mice during the 30-min AngII infusion. However, we cannot exclude the important effect of renal mPGES-1 in hypertenison because in previous reports $^{[29,30]}$, the antihypertensive effect of renal mPGES1-derived PGE2 appears to be critical in chronic settings, including long-term AngII infusion and high salt diet.

To further characterize the underlying mechanism involved in the hypotensive effect of mPGES-1-derived PGE2 during acute infusion of AngII, we measured PGE2 release from isolated mesenteric arteries and found that acute AngII treatment resulted in a significant increase in PGE2 release in wild-type mice but not $\mathrm{mPGES}^{-1^{-/}}$mice. Based on the fact that acute infusion of angiotensin II did not yield a significant mPGES-1 protein induction, we speculated that angiotensin II may stimulate the release of PGE2 through preexisting mPGES-1 protein in the vessels. Because of the vasodialatory nature of mPGES-1-derived PGE2, this finding demonstrates that mPGES-1 is critical for vascular PGE2 release after acute AngII treatment and that its deficiency lowers vascular PGE2 levels, leading to an exaggerated hypertensive response to AngII.

The vascular expression of mPGES-1 and the blunted PGE2 release after AngII treatment in mesenteric arteries of mPGES$1^{-/-}$mice strongly support the possibility that mPGES-1 expression in peripheral resistant vessels plays an important role in modulating vascular tone and blood pressure. A direct functional interaction between AngII and mPGES-1 activity was further demonstrated by the finding that the constrictor effects of AngII were greatly exaggerated by mPGES-1 gene ablation, which is consistent with a role of mPGES-1-derived PGE2 in buffering AngII-induced vasoconstriction.

Increasing evidence suggests that genetic background has a significant impact on blood pressure. Although the role of mPGES-1 on blood pressure has been reported by several groups, the results reach an inconsistent conclusion. Jia et al found that on a mixed DBA/1lacJxC57BL/6 background, mPGES-1 null mice developed more severe hypertension compared to the wild-type controls in response to AngII infusion and chronic salt loading ${ }^{[29,30]}$. Similarly, in our present study, we found that mPGES-1 deletion on a pure C57BL/6 background caused a hypertensive response to acute AngII infusion. However, other studies have shown no influence of mPGES-1 deletion on blood pressure on mice with a DBA/11acj background that were fed with a high salt diet ${ }^{[32]}$. A recent report by Facemire et al demonstrated that infusing mPGES-1-deficient mice with AngII resulted in a significant vasopressor response on a $129 / \mathrm{SvEv}$ background but not on a DBA/11acJ background ${ }^{[55]}$. These observations collectively point to a critical role of genetic background in mediating mPGES-1's effect on blood pressure regulation.

In summary, we demonstrate that mPGES-1 was constitutively expressed in the VSMCs of peripheral resistant vessels of mice. The mPGES-1/- mice exhibit an exaggerated pressor response to acute AngII infusion. AngII treatment resulted in a blunted PGE2 secretion and enhanced vasoconstriction in isolated mesenteric arteries of mPGES-1 $1^{-/-}$mice. These findings provide compelling evidence that vascular mPGES1-derived PGE2 acts as an important tonic vasodilator for maintaining blood pressure homeostasis in pathophysiological settings. Thus, pharmacological targeting of mPGES-1 may not represent an alternative for avoiding the undesirable cardiovascular effects of COX-2 inhibitors.

\section{Acknowledgements}

We thank Drs D RIENDEAU D and JA MANCINI (Merck Frosst Centre for Therapeutic Research, Kirkland, Quebec, Canada) for providing the mPGES-1 gene-deficient mice. This work was supported by the National Natural Science Foundation of China (grant 30530340/30725033), the Ministry of Science and Technology (2006CB503907), and the National Institute of Diabetes and Digestive and Kidney Diseases (RO1 065074-04 \& PO1DK38226). 


\section{Author contribution}

Prof You-fei GUAN designed the research and revised the manuscript; Prof Matthew-D BREYER and Prof Yuan-sheng GAO helped with part of the research design; Dong-juan ZHANG and Li-hong CHEN conducted the research, analyzed the data and wrote the paper; Ya-hua ZHANG, Guang-rui YANG, Dou DOU, Pan ZHAO, and Xiao-mu KONG helped with part of the research; Xiao-yan ZHANG, Ming-fen WEI, and Dan PU helped write the manuscript.

\section{References}

1 Samuelsson B, Morgenstern R, Jakobsson PJ. Membrane prostaglandin E synthase-1: a novel therapeutic target. Pharmacol Rev 2007; 59: 207-24.

2 Jakobsson PJ, Thoren S, Morgenstern R, Samuelsson B. Characterization of microsomal, glutathione dependent prostaglandin E synthase. Adv Exp Med Biol 2002; 507: 287-91.

3 Thoren S, Weinander R, Saha S, Jegerschold C, Pettersson PL, Samuelsson B, et al. Human microsomal prostaglandin E synthase-1: purification, functional characterization, and projection structure determination. J Biol Chem 2003; 278: 22199-209.

4 Han R, Tsui S, Smith TJ. Up-regulation of prostaglandin E2 synthesis by interleukin-1beta in human orbital fibroblasts involves coordinate induction of prostaglandin-endoperoxide $\mathrm{H}$ synthase- 2 and glutathione-dependent prostaglandin E2 synthase expression. J Biol Chem 2002; 277: 16355-64.

5 Shinji Y, Tsukui T, Tatsuguchi A, Shinoki K, Kusunoki M, Suzuki K, et al. Induced microsomal PGE synthase-1 is involved in cyclooxygenase2-dependent PGE2 production in gastric fibroblasts. Am J Physiol Gastrointest Liver Physiol 2005; 288: G308-15.

6 Murakami M, Kudo I. Prostaglandin E synthase: a novel drug target for inflammation and cancer. Curr Pharm Des 2006; 12: 943-54.

7 Trebino CE, Stock JL, Gibbons CP, Naiman BM, Wachtmann TS, Umland JP, et al. Impaired inflammatory and pain responses in mice lacking an inducible prostaglandin E synthase. Proc Natl Acad Sci U S A 2003; 100: 9044-9.

8 Friesen RW, Mancini JA. Microsomal prostaglandin E2 synthase-1 (mPGES-1): a novel anti-inflammatory therapeutic target. J Med Chem 2008; 51: 4059-67.

9 Soodvilai S, Jia Z, Wang MH, Dong Z, Yang T. mPGES-1 deletion impairs diuretic response to acute water loading. Am J Physiol Renal Physiol 2009; 296: F1129-35.

10 Murakami M, Naraba H, Tanioka T, Semmyo N, Nakatani Y, Kojima $\mathrm{F}$, et al. Regulation of prostaglandin E2 biosynthesis by inducible membrane-associated prostaglandin E2 synthase that acts in concert with cyclooxygenase-2. J Biol Chem 2000; 275: 32783-92.

11 von Rahden BH, Stein HJ, Hartl SA, Theisen J, Stigler B, Siewert JR, et al. Expression of prostaglandin $E$ synthase in Barrett's cancer. Dis Esophagus 2008; 21: 304-8.

12 Watanabe K, Kurihara K, Suzuki T. Purification and characterization of membrane-bound prostaglandin $E$ synthase from bovine heart. Biochim Biophys Acta 1999; 1439: 406-14.

13 Tanikawa N, Ohmiya Y, Ohkubo H, Hashimoto K, Kangawa K, Kojima M, et al. Identification and characterization of a novel type of membraneassociated prostaglandin E synthase. Biochem Biophys Res Commun 2002; 291: 884-9.

14 Murakami M, Nakashima K, Kamei D, Masuda S, Ishikawa Y, Ishii $\mathrm{T}$, et al. Cellular prostaglandin E2 production by membrane-bound prostaglandin E synthase-2 via both cyclooxygenases-1 and -2. J Biol Chem 2003; 278: 37937-47.
15 Tanioka T, Nakatani Y, Semmyo N, Murakami M, Kudo I. Molecular identification of cytosolic prostaglandin E2 synthase that is functionally coupled with cyclooxygenase-1 in immediate prostaglandin E2 biosynthesis. J Biol Chem 2000; 275: 32775-82.

16 Gudis K, Tatsuguchi A, Wada K, Futagami S, Nagata K, Hiratsuka T, et al. Microsomal prostaglandin E synthase (mPGES)-1, mPGES-2 and cytosolic PGES expression in human gastritis and gastric ulcer tissue. Lab Invest 2005; 85: 225-36.

17 Guan Y, Zhang Y, Wu J, Qi Z, Yang G, Dou D, et al. Antihypertensive effects of selective prostaglandin E2 receptor subtype 1 targeting. J Clin Invest 2007; 117: 2496-505.

18 Zhang Y, Guan Y, Schneider A, Brandon S, Breyer RM, Breyer MD. Characterization of murine vasopressor and vasodepressor prostaglandin E(2) receptors. Hypertension 2000; 35: 1129-34.

19 Hao CM, Breyer MD. Physiological regulation of prostaglandins in the kidney. Annu Rev Physiol 2008; 70: 357-77.

20 Hao CM, Breyer MD. Physiologic and pathophysiologic roles of lipid mediators in the kidney. Kidney Int 2007; 71: 1105-15.

21 Breyer MD, Breyer RM. G protein-coupled prostanoid receptors and the kidney. Annu Rev Physiol 2001; 63: 579-605.

22 Izhar M, Alausa T, Folker A, Hung E, Bakris GL. Effects of COX inhibition on blood pressure and kidney function in ACE inhibitor-treated blacks and hispanics. Hypertension 2004; 43: 573-7.

23 Sowers JR, White WB, Pitt B, Whelton A, Simon LS, Winer N, et al. The effects of cyclooxygenase- 2 inhibitors and nonsteroidal anti-inflammatory therapy on 24-hour blood pressure in patients with hypertension, osteoarthritis, and type 2 diabetes mellitus. Arch Intern Med 2005; 165: 161-8.

24 Grosser T, Fries S, FitzGerald GA. Biological basis for the cardiovascular consequences of COX-2 inhibition: therapeutic challenges and opportunities. J Clin Invest 2006; 116: 4-15.

25 Farkouh ME, Kirshner H, Harrington RA, Ruland S, Verheugt FW, Schnitzer TJ, et al. Comparison of lumiracoxib with naproxen and ibuprofen in the Therapeutic Arthritis Research and Gastrointestinal Event Trial (TARGET), cardiovascular outcomes: randomised controlled trial. Lancet 2004; 364: 675-84.

26 Bresalier RS, Sandler RS, Quan H, Bolognese JA, Oxenius B, Horgan K, et al. Cardiovascular events associated with rofecoxib in a colorectal adenoma chemoprevention trial. N Engl J Med 2005; 352: 1092102.

27 Zhang J, Ding EL, Song Y. Adverse effects of cyclooxygenase 2 inhibitors on renal and arrhythmia events: meta-analysis of randomized trials. Jama 2006; 296: 1619-32.

28 Bombardier C, Laine L, Reicin A, Shapiro D, Burgos-Vargas R, Davis B, et al. Comparison of upper gastrointestinal toxicity of rofecoxib and naproxen in patients with rheumatoid arthritis. VIGOR Study Group. N Engl J Med 2000; 343: 1520-8, 2 p following 28.

29 Jia Z, Zhang A, Zhang H, Dong Z, Yang T. Deletion of microsomal prostaglandin E synthase-1 increases sensitivity to salt loading and angiotensin II infusion. Circ Res 2006; 99: 1243-51.

30 Jia Z, Guo X, Zhang H, Wang MH, Dong Z, Yang T. Microsomal prostaglandin synthase-1-derived prostaglandin E2 protects against angiotensin II-induced hypertension via inhibition of oxidative stress. Hypertension 2008; 52: 952-9.

31 Francois H, Facemire C, Kumar A, Audoly L, Koller B, Coffman T. Role of microsomal prostaglandin E synthase 1 in the kidney. J Am Soc Nephrol 2007; 18: 1466-75.

32 Cheng Y, Wang M, Yu Y, Lawson J, Funk CD, Fitzgerald GA. Cyclooxygenases, microsomal prostaglandin E synthase-1, and cardiovascular function. J Clin Invest 2006; 116: 1391-9.

33 Qi Z, Hao CM, Langenbach RI, Breyer RM, Redha R, Morrow JD, et al. 
Opposite effects of cyclooxygenase- 1 and -2 activity on the pressor response to angiotensin II. J Clin Invest 2002; 110: 61-9.

34 Uematsu S, Matsumoto M, Takeda K, Akira S. Lipopolysaccharidedependent prostaglandin $E(2)$ production is regulated by the glutathione-dependent prostaglandin $\mathrm{E}(2)$ synthase gene induced by the Toll-like receptor 4/MyD88/NF-IL6 pathway. J Immunol 2002; 168: 5811-6.

35 Yang G, Chen L, Zhang Y, Zhang X, Wu J, Li S, et al. Expression of mouse membrane-associated prostaglandin E2 synthase-2 (mPGES-2) along the urogenital tract. Biochim Biophys Acta 2006; 1761: 145968.

36 Guo Z, Van Remmen H, Yang H, Chen X, Mele J, Vijg J, et al. Changes in expression of antioxidant enzymes affect cell-mediated LDL oxidation and oxidized LDL-induced apoptosis in mouse aortic cells. Arterioscler Thromb Vasc Biol 2001; 21: 1131-8.

37 Wang X, Tong M, Chinta S, Raj JU, Gao Y. Hypoxia-induced reactive oxygen species downregulate ETB receptor-mediated contraction of rat pulmonary arteries. Am J Physiol Lung Cell Mol Physiol 2006; 290: L570-8.

38 LaCroix C, Freeling J, Giles A, Wess J, Li YF. Deficiency of M2 muscarinic acetylcholine receptors increases susceptibility of ventricular function to chronic adrenergic stress. Am J Physiol Heart Circ Physiol 2008; 294: H810-20.

39 Yang T. Microsomal prostaglandin E synthase-1 and blood pressure regulation. Kidney Int 2007; 72: 274-8.

40 Fierro-Carrion GA, Ram CV. Nonsteroidal anti-inflammatory drugs (NSAIDs) and blood pressure. Am J Cardiol 1997; 80: 775-6.

41 Siragy HM, Senbonmatsu T, Ichiki T, Inagami T, Carey RM. Increased renal vasodilator prostanoids prevent hypertension in mice lacking the angiotensin subtype-2 receptor. J Clin Invest 1999; 104: 181-8.

42 Feuerstein G, Adelberg SA, Kopin IJ, Jacobowitz DM. Hypothalamic sites for cardiovascular and sympathetic modulation by prostaglandin E2. Brain Res 1982; 231: 335-42.

43 Hristovska AM, Rasmussen LE, Hansen PB, Nielsen SS, Nusing RM, Narumiya S, et al. Prostaglandin E2 induces vascular relaxation by E-prostanoid 4 receptor-mediated activation of endothelial nitric oxide synthase. Hypertension 2007; 50: 525-30.
44 Ueno N, Takegoshi Y, Kamei D, Kudo I, Murakami M. Coupling between cyclooxygenases and terminal prostanoid synthases. Biochem Biophys Res Commun 2005; 338: 70-6.

45 Chandrasekharan S, Foley NA, Jania L, Clark P, Audoly LP, Koller BH. Coupling of COX-1 to mPGES1 for prostaglandin E2 biosynthesis in the murine mammary gland. J Lipid Res 2005; 46: 2636-48.

46 Vila L. Cyclooxygenase and 5-lipoxygenase pathways in the vessel wall: role in atherosclerosis. Med Res Rev 2004; 24: 399-424.

47 Davidge ST. Prostaglandin H synthase and vascular function. Circ Res 2001; 89: 650-60.

48 Soler M, Camacho M, Escudero JR, Iniguez MA, Vila L. Human vascular smooth muscle cells but not endothelial cells express prostaglandin E synthase. Circ Res 2000; 87: 504-7.

49 Morinelli TA, Walker LP, Ullian ME. COX-2 expression stimulated by angiotensin II depends upon AT1 receptor internalization in vascular smooth muscle cells. Biochim Biophys Acta 2008; 1783: 1048-54.

50 Jaimes EA, Zhou MS, Pearse DD, Puzis L, Raij L. Upregulation of cortical COX-2 in salt-sensitive hypertension: role of angiotensin II and reactive oxygen species. Am J Physiol Renal Physiol 2008; 294: F385-92.

51 Young W, Mahboubi K, Haider A, Li I, Ferreri NR. Cyclooxygenase-2 is required for tumor necrosis factor-alpha- and angiotensin II-mediated proliferation of vascular smooth muscle cells. Circ Res 2000; 86: 906-14.

52 Cheng HF, Harris RC. Cyclooxygenases, the kidney, and hypertension. Hypertension 2004; 43: 525-30.

53 Camacho M, Gerboles E, Escudero JR, Anton R, Garcia-Moll X, Vila L. Microsomal prostaglandin E synthase-1, which is not coupled to a particular cyclooxygenase isoenzyme, is essential for prostaglandin E(2) biosynthesis in vascular smooth muscle cells. J Thromb Haemost 2007; 5: 1411-9.

54 Breyer MD, Breyer RM. Prostaglandin E receptors and the kidney. Am J Physiol Renal Physiol 2000; 279: F12-23.

55 Facemire CS, Griffiths R, Audoly LP, Koller BH, Coffman TM. The impact of microsomal prostaglandin $\mathrm{E}$ synthase 1 on blood pressure is determined by genetic background. Hypertension 2010; 55: 531-8. 